\title{
A Review on Transitional Implications for Retiring Elite Athletes: What Happens When the Spotlight Dims?
}

\author{
Jenniefer L. Smith ${ }^{1}$ and Alexandra McManus*,2 \\ ${ }^{I}$ The University of Western Australia, Faculty of Medicine and Dentistry, Perth, Australia \\ ${ }^{2}$ Curtin Health Innovation Research Institute, Faculty of Health Sciences, Curtin University of Technology, Perth, \\ Australia
}

\begin{abstract}
The purpose of this investigation was to examine the factors affecting an elite athlete's transition from the sports environment, and identify opportunities for interventions to facilitate a positive transition into post-sports life. Articles were identified through a systematic keyword and database search and were examined using the components of Schlossberg's Model of Human Adaptation to Transition (characteristics of the transition, the individual and the pre and post environment). The greatest contributors to a difficult transition include involuntary retirement (injury or deselection), a strong, exclusive athletic identity, and lack of pre-retirement planning and support services. However, gaps exist in the scope of programs to address broader adaptation issues. Greater emphasis should be directed towards the psychological, social and physical transitions experienced by elite athletes prior to and after retirement to ensure a positive adaptation into post-sports life.
\end{abstract}

Key Words: Transition, Elite sport, Retirement, Deselection, Injury.

\section{BACKGROUND}

The dynamic nature of transitional life stages has facilitated the growth of evidence-based literature in this field over past decades. While most transitions are foreseeable and allow a period of preparation, others are unanticipated, with little or no forward planning. Regardless of the preceding factors, transitional periods are often accompanied by a reevaluation of one's life, including a shift in self-identity and a re-direction of energies [1]. Such transformations may affect how individuals perceive themselves, their abilities and the quality of their lives, and depending upon the characteristics of the transition, could also impact on subjective wellbeing $[2,3]$.

A significant proportion of transitional research has examined the experiences of workforce retirees to identify adaptation skills required for a smooth transition into retirement $[4,5]$. The transitional perspective examines the retirement process as multidimensional and has been applied to different population groups, including the adaptation faced by elite athletes upon their sporting career termination $[4,6]$.

Competitive sports retirement represents a unique period of life change, as, unlike retirement from other careers, it usually occurs early in life [7]. The sports environment creates a lifestyle based upon commitment, discipline and routine that is designed to shelter an athlete from external distractions [3]. During the late 1990s, transitional research recognised sports retirement as neither a singular, all-ending event (time of retirement) nor a single state of existence (a

*Address correspondence to this author at the Centre for Behavioural Research in Cancer Control, Curtin University of Technology, GPO Box U1987, Perth, Western Australia; Tel: +61 89266 2115; Fax: +61 89266 2608; E-mail: A.Mcmanus@curtin.edu.au former elite athlete) $[1,6]$. This perspective has enabled re search into sports retirement to progress from an exclusive focus on one transition (the retirement event) to a broader life-span perspective encompassing non-athletic transitions at psychological, psychosocial, academic and vocational levels $[6,8,9]$.

Furthermore, research has progressed from identifying the causes and consequences of sports retirement to investigating factors influencing the quality of career transitions and strategies preparing athletes for life after sport [8]. Conceptual models facilitating this broader approach, such as Schlossberg's Model of Human Adaptation to Transition, have contributed to a greater understanding of the sports retirement process. Schlossberg's model considers characteristics of the individual, the transition and the pre and post retirement environments in determining adaptation success $[4,9,10]$. Despite this, there is still a lack of effective interventions addressing the transitional needs of athletes before, during and after career termination.

Aside from identifying trends in the factors influencing a positive or negative retirement experience, limited exploration has been directed towards the broader psychological, social and physical adjustments encountered by elite athletes upon career termination. Studies investigating past athletes' perceptions of retirement suggest the sports environment may lead to a poor sense of personal control due to the management of daily routines, behaviours and decision-making by coaches and sports associations [11,12]. The structured nature of the elite sports environment may foster a false sense of security in athletes by protecting them against influences outside the sports career [11]. Such 'protection' may inhibit an athlete's ability to adjust and cope with their nonathletic identity upon retirement. Given the dramatic lifestyle 
changes facing retiring athletes, a sense of control over their own lives, in particular enhanced self-efficacy, will play a fundamental role in fostering positive mental health and their ability to cope with lifestyle change [13].

Whilst a number of sporting institutions offer some athlete support services in preparation for post-sports life, the majority are largely directed towards ensuring athletes are pre-prepared academically and/or professionally upon retirement [14-16]. However, most programs lack depth in areas such as general social skills, self-esteem and resiliency skills and coping strategies for lifestyle changes. For instance, elite athletes receive structured and enforced nutritional and sport-specific physical activity instruction to enhance their athletic performance. Once this support ceases (often instantaneously) a retired athlete's ability to cope with an unfamiliar lifestyle may be inhibited through a lack of general lifestyle as well as specific professional knowledge and skills.

A further concern surrounds the retiring athlete's readiness to cope with a range of social pressures avoided during their sports career. Evidence suggests physical activity and sport act as protective factors against stress, depression and/or unsettling behaviours (risk taking, experimental behaviours and drug use) [17]. Elite athletes may not experience the gambit of psychological, social or physical developmental stages experienced by their non-athletic peers, leaving them ill-equipped for lifestyle changes upon retirement. Factors such as premature retirement due to injury or deselection [5-7,15,16,18-21]; a strong, exclusive athletic identity [5, 7, 21-24]; and a lack of pre-retirement planning and support services have been identified as the greatest contributors to a difficult transition from elite sports $[7,8,11$, $25,26]$. Despite this, little is known about how athletes cope with their retirement across various physical, psychological and social levels. Athletes who are not provided with coping skills for post-sports adaptation and resistance to social pressures may be at greater risk of adverse physical, social and psychological outcomes [3, 5, 7, 11, 12, 18, 20, 27, 28].

\section{METHODS}

This paper provides a systematic review of the sports retirement literature, and identifies issues that have the potential for creating multi-strategic services for current and retired elite athletes. The primary aim of the review was to investigate factors affecting an elite athlete's transition from the sports environment, and to identify potential components of athlete interventions likely facilitate a positive transition into post-sports life.

The review used a well-defined search methodology and specific selection criteria to identify several areas that should be the focus of future programs. The search strategy involved a combination of keywords to identify appropriate publications. These included: athlete/athletic, retirement, sports, transition/s, programs, identity. Keyword searches were conducted in the following databases: SPORTDiscus; Health and Medical Complete; ProQuest 5000; Medline; Science Direct; Info Trac OneFile; AusportMed (sports medicine) and PsychINFO. The reference lists of review articles were also systematically reviewed for relevant publications not identified through the electronic database search.
The review included articles from 1990 onwards that were selected based upon research design and methodology, study sample characteristics, and reliable research outcomes. Review findings were catergorised into the components of Schlossberg's Model of Human Adaptation to Transition (characteristics of the transition, the individual and the pre and post retirement environments). The model was used to systematically examine the major determinants influencing the quality of transition from elite sports. This paper identifies and examines the determinants of an elite athlete's ability to cope with lifestyle changes after retirement. These are discussed under the three categories of Schlossberg's model (characteristics of the transition; characteristics of the individual; and characteristics of the pre and post environment). Brief recommendations are included at the end of each section followed by a discussion and overall recommendations.

\section{A REVIEW OF THE SPORTS RETIREMENT LIT- ERATURE}

\section{Characteristics of the Transition}

A significant cause of sports career termination is the unforeseeable nature of sports injuries [5-7, 15, 16, 18, 19]. Premature retirement due to injury can impact upon the quality of the transition an athlete experiences [5, 20, 27]. A reduction in the gradualness of the adaptation process, the nonaccomplishment of sports-related goals, and the degree of preparation for a new life direction lead to a perceived lack of control in an athlete [5]. As a result, an athlete may become more susceptible to psychological and psychosocial difficulties such as lower self control, self esteem and self respect, feelings of anger, anxiety and depression, and also substance abuse $[11,18,20,28]$.

In addition to injury-related retirement, deselection is a significant causal factor that can negatively impact upon an athlete's ability to adjust during their retirement [3, 20, 27]. Although the consequences of premature retirement due to deselection have been documented, there is a lack of evidence regarding the skills required to cope in this situation. Whereas injury-related retirements relinquish a sense of personal control to some extent, the athlete is spared the esteemdamaging message that they weren't good enough [7]. Deselection on the other hand may be more foreseeable, however it may also be associated with doubts surrounding athletic ability, leading to decreased self-esteem and self-confidence [7].

Sports retirement research has established an association between involuntary sports career termination and difficulties in adjusting to a non-athletic lifestyle [2, 5, 7, 11, 20, 24, 29]. Despite such evidence, there appears to be a lack of commitment towards early intervention services that seek to reduce difficulties associated with premature and involuntary retirement. Maintaining the development of an athlete outside the sports environment, and providing services that address general life skills along with professional and academic skills will facilitate a positive transition into retirement. With organisational structures in place to support the development of elite athletes across disciplines, there is capacity for elite sporting institutions to expand athlete services within their existing infrastructure. 


\section{Characteristics of the Individual}

The dynamic nature of retirement from elite sport is often accompanied by an initial sense of loss, followed by a period of re-orientation, growth and adaptation [22, 28, 30]. Several studies suggest transitional athletes undergo significant psychosocial adjustments involving a shift in identity from that of an athlete, to the establishment of a new social status in their post-sports life [12, 22, 23, 28, 31, 32]. The prevalence of the athletic identity over other social roles can ultimately determine the extent of psychological difficulties experienced and coping skills utilised during the transition to postsports life [5]. Athletes possessing a strong, exclusive athletic identity seem to be most at risk of experiencing psychological and psychosocial difficulties upon retirement and are less likely to have explored future career, education and lifestyle options $[7,12,18,22,30]$. In many cases, athletic identity is formed and internalised early in life, dominating over other social roles that usually characterise adolescence and early adulthood [7].

There is a lack of published research addressing the effect of age and stage of life associated with athletic identity and the retirement transition. Athletes involved in elite sports from an early age, such as gymnastics, more strongly commit to an athletic identity due to a lack of exposure to other life experiences during childhood [23]. However the sports career in gymnastics is relatively short-lived, with most athletes retiring in their late teens or early twenties. As such, the opportunity to develop academic and professional skills after involuntary or voluntary retirement is still within a timely stage of life. Conversely, sports fostering athletes for a longer duration may hold greater consequences upon retirement, particularly in their ability to resocialise from their athletic identity into non-sport participatory roles [23].

Athletic identity, age and stage of life should therefore be considered important individual characteristics that impact upon the transitional quality into post-sports life. Coaches and sporting associations should not view non-athletic transitions (eg. academic, vocational, social) occurring outside the sports environment as negative influences on an athlete's sporting career. Greater consideration of the benefits of encouraging a balanced self-concept and identity for life, during and after sport, should be fostered within the sports environment $[3,23]$.

\section{Characteristics of the Pre and Post Environment}

During involvement in elite sport, educational, occupational and social decisions are often considered secondary to sports-related goals. The majority of athlete assistance programs identified in the literature focus on enhancing educational and professional-related skills in athletes. While there is evidence of the benefits of such programs, particularly for career direction after sport, the sporadic nature and lack of available funding for these programs present barriers for enhancing these initiatives to address broader retirement issues such as social integration and coping skills $[8,14,15]$.

The literature reviewed on athlete assistance services was restricted to programs implemented in Australia, however similar programs have been established in the United Kingdom, United States of America and Canada [8]. The first transitional program designed for retiring elite athletes in Australia was introduced after the 1988 Seoul Olympics [25]. The initiation of the Lifeskills for Elite Athletes Program (LEAP) was prompted by a lack of career options upon sports retirement. Following this, the Athlete and Career Education (ACE) program was established in 1990 and the Olympic Job Opportunity Program (OJOP) in 1992 [25].

The development of a coordinated national approach to the ACE program has allowed athletes based within their state sporting institutions to utilise the same support services offered to those relocating to National Training Centres [8]. The Australian ACE program aims to develop educational and vocational skills to facilitate the planning of nonsporting careers, however recent investigations demonstrated low uptake rates among the target group [26]. Of the 878 active athletes surveyed (across 48 sports) who could have benefited from the ACE program, services were used by less than $1 \%(0.7 \%)$ [26]. Results from this study also demonstrated a low perceived importance from these athletes towards retirement issues [26, 34].

A national evaluation of the ACE Program identified accessibility and availability as significant factors that reduced the effectiveness of the program [14]. Key barriers to the success of the ACE program included a lack of awareness in athletes living away from major ACE service centres, a need to develop alternative delivery modes to enhance program reach, and a need for information and services to be transferable and consistent across sporting institutions to cater for relocation [14]. Such findings suggest programs designed for elite athletes must be flexible in their delivery and accommodate a range of strategies to engage the target group more successfully.

The literature reviewed on past and existing athlete assistance programs within Australia indicates a lack of systematic public support for elite athletes after their sports career [27]. In addition to developing programs that are accessible and relevant to elite athletes, programs should assist athletes to adjust to a less regimented lifestyle after retirement [3]. Current programs seem to largely target elite athletes still competing, with little attention directed to recently retired athletes who find themselves in an 'in-between' social status (still perceived as an athlete yet trying to assume other identities) [3]. This is a crucial time for continued intervention to influence the quality and development of an athlete into postsport life, and prevent difficulties associated with the transition.

\section{DISCUSSION}

Mapping transitional difficulties of sports retirement provides strong justification for developing interventions based on a more comprehensive approach. Transitional research consistently reports retirement-related issues at the psychological (identity crisis, decreased self esteem and self worth, emotional problems and substance abuse), physical (injuries, general health problems, issues with detraining, and dietary and physical activity related problems) and psychosocial (social and cultural loneliness, lack of professional qualifications and decline of financial income) levels $[3,5,7,11,12$, $18,20,27,28]$ Ho.wever, due to a lack of methodological 
rigor across published sports retirement research, it is not possible to report the prevalence of these difficulties in the elite sports population.

Barriers restricting the effectiveness of current programs for elite athletes include a narrow perspective of the issues that need to be addressed, poor service access rates from elite athletes in Australia, and that contact occurs after an athlete experiences difficulty with their transition [26]. Early intervention strategies to prevent retirement-related problems should be directed towards all elite athletes, across sports and be continued into retirement. Multi-faceted programs encompassing the comprehensive nature of lifespan development that consider an athlete's gender, age and cultural perspectives should be instituted within each elite sporting body's strategic plan [33,34].

There is significant opportunity for optimising the timing and type of assistance provided during the transitional period. Retiring athletes require ongoing institutional support to maintain their feelings of self worth as they transfer from an elite sporting career [1]. An avenue yet to be explored is the potential for ongoing support through formal implementation of a progressive detraining program [3]. This would allow support personnel to assist athletes to cope with significant lifestyle changes during the initial transition period, and protect them from abrupt physical and social transformations that may elicit feelings of poor self-worth and selfefficacy [3].

With many elite athletes retiring after the Olympics, it is timely to conduct research into sports retirement to investigate the factors associated with this transition. To achieve a sustainable approach to interventions targeting elite athletes, the formation of stronger partnerships and greater collaboration between those directly involved in an athlete's sporting performance is required. Furthermore, institutional support is essential to establish a coordinated approach that will enhance the overall development of elite athletes.

\section{CONCLUSION}

Upon retirement, athletes should be equipped with a balanced and diverse range of life competencies to enable a smooth transition personally, socially, professionally/academically and financially into post-sports life. Opportunities exist to develop professional skills and to foster broader life skills that will facilitate a smoother transition from elite sports. Such efforts will help to build a 'non-athletic' identity prior to retirement and may help to reduce the occurrence of a 'transitional burden'. To achieve this, researchers and sporting associations should draw on the experiences of former athletes when developing a program that will guide athletes to make appropriate lifestyle choices and minimise the stress of transition for current and recently retired athletes. To ensure success and sustainability of athlete transition programs, strategies chosen must accommodate the range of individual circumstances and adaptation phases faced by elite athletes, before and after retirement. These strategies will assist in facilitating a smooth transition for elite athletes as they move beyond the realm of sport.

\section{REFERENCES}

[1] Chow BC. Moving on? Elite Hong Kong female athletes and retirement from competitive sport. Women Sport Phys Act J 2001; 10(2): 47.

[2] Kim J, Moen P. Is retirement good or bad for subjective wellbeing? Curr Dir Psychol Sci 2001; 10: 83-6.

[3] Stephan Y, Bilard J, Ninot G, Delignieres D. Repercussions of transition out of elite sport on subjective well-being: a one year study. J App Sports Psychol 2003; 15: 354-71.

[4] Lavallee D. Theoretical perspectives on career transitions in sport. In: Lavallee DWP, Ed. Career transitions in sport. International Perspectives Morgantown, WV: Fitness Inf Technol 2000; pp. 128.

[5] Cecic-Erpic S, Wylleman P, Zupancic M. The effect of athletic and non-athletic factors on the sports career termination process. Psychol Sport Exerc 2004; 5: 45-59.

[6] Wylleman P, Alferman D, Lavallee D. Career transitions in sport: European perspectives. Psychol Sport Exerc 2004; 5: 7-20.

[7] Webb W, Nasco SA, Riley S, Headrick B. Athletic identity and reactions to retirement from sports. J Sports Behav 1998; 3: 33862.

[8] Anderson D, Morris T. Athlete lifestyle programs. In: Lavallee D, Wylleman P, Ed. Career transitions in sport: International Perspectives. Morgantown, WV: Fitness Inf Technol 2000; pp. 59-80.

[9] Schlossberg N. A model for analysing human adaptation to transition. Counsel Psychol 1981; 9: 2-18.

[10] Schlossberg N. Counseling adults in transition. New York: Springer 1984.

[11] Werthner P, Orlick T. Retirement experiences of successful Olympic athletes. Int J Sports Psychol 1986; 17: 337-63.

[12] Kerr G, Dacyshyn A. The retirement experiences of female elite gymnasts. J App Sports Psychol 2000; 12: 115-33.

[13] Bandura A. Self-efficacy: The exercise of control. New York: Freeman 1997.

[14] Gorely T, Bruce D, Teale B. Athlete career and education program 1997 evaluation. Brisbane: University of Queensland 1998.

[15] Lavallee D, Grove JR, Gordon S. The causes of career termination from sport and their relationship to post-retirement adjustment among elite amateur athletes in Australia. Aust Psychol 1997; 32(2): 131-35.

[16] Petitpas A, Champagne D, Chartrand J, Danish S, Murphy S. Athlete's guide to career planning. Keys to success from the playing field to professional life. Champaign, Il: Human Kinetics 1997.

[17] Ferron C, Narring F, Cauderay M, Michaud PA. Sport activity in adolescence: associations with health perceptions and experimental behaviours. Health Educ Res 1999; 14(2): 225-33.

[18] Crook J, Robertson SE. Transitions out of elite sport. Intern J Sports Psychol 1991; 22: 115-127.

[19] Brickell T, Stewart E, O'Sign D, Thirne G. Athlete Transition Guidelines. Perth: Western Australian Institute of Sport 1999.

[20] Alfermann D. Causes and consequences of sport career termination. In: Lavallee D, Wylleman P, Ed. Career transitions in sport: International Perspectives, Morgantown, WV: Fitness Inf Technol 2000; pp. 45-58.

[21] Taylor J, Ogilvie BC. A conceptual model of adaptation to retirement among athletes. J App Sports Psychol 1994; 6: 1-20.

[22] Brewer BW, Van Raalte JL, Linder DE. Athletic identity: Hercules' muscle or Achilles' heel? Int J Sports Psychol 1993; 24: 237-54.

[23] Brewer B, Van Raalte JL, Petitpas AJ. Self identity issues in sport career transitions. In: Lavallee D, Wylleman P, Ed. Career transitions in sport: International Perspectives Morgantown, WV: Fitness Inf Technol 2000; pp. 27-43.

[24] Green SL. Relationships among athletic identity, coping skills, social support, and the psychological impact of injury in recreational participants. J App Sports Psychol 2001; 13(1): 40-59.

[25] Gordon S. Career transitions in competitive sport. In: Morris T, Summers J, Ed. Sport Psychology: Theory, applications and issues. Brisbane: Jacaranda Wiley 1995; pp. 474-501.

[26] Gorely T, Lavallee D, Bruce D, Teale B, Lavallee R. A sampling of perceptions of potential users of the Australian Athlete Career and Education program. Acad Athletic J 2001; 15: 11-21.

[27] Alfermann D, Stambulova NB, Zemaityte A. Reactions to sport career termination: a cross-national comparison of German, Lithuanian and Russian athletes. Psychol Sport Exerc 2004; 5: 61-75. 
[28] Mihovilovic M. The status of former sportsmen. Int Rev Sport Sociol 1968; 3: 73-93.

[29] Coakley J. Leaving competitive sport: retirement or rebirth? Quest 1983; 35: 1-11.

[30] Brandao MRF, Winterstein P, Pinheiro C, Agresta M, Akel MC, Martini L. Career transition of former Brazilian top level athletes. In: Papaioannou A, Goudas M, Theodorakis Y, Ed. 10th World Congress of Sport Psychology; Skiatos: Int Soc Sports Psychol 2001; pp. 1-2.

[31] Sinclair DA, Orlick T. Positive transitions from high performance sport. Sports Psychol 1993; 7: 138-50.
[32]

Stambulova NB. Sports career termination of Russian athletes: readiness to the transition. In: Papaioannou A, Goudas M, Theodorakis Y, Ed. 10th World Congress of Sport Psychology; Skiatos: Int Soc Sports Psychol 2001; pp. 29-31.

[33] North J, Lavallee D. An investigation of potential users of career transition services in the United Kingdom. Psychol Sport Exerc 2004; 5: 77-84.

[34] Ogilvie B, Taylor J. Career termination issues among elite athletes. Life-span Dev 1993; 35: 761-73.

Received: September 09, 2008

Revised: November 12, 2008

Accepted: November 17, 2008

(c) Alexandra McManus; Licensee Bentham Open.

This is an open access article licensed under the terms of the Creative Commons Attribution Non-Commercial License (http://creativecommons.org/licenses/by-nc/3.0/) which permits unrestricted, non-commercial use, distribution and reproduction in any medium, provided the work is properly cited. 